\title{
The threefold self and the four options: self- monitoring one's daily emotional spin cycle
}

\begin{abstract}
A simplified general theory of self-change was presented in written instructions to college students that gave them a systematic and objective way of perceiving and monitoring their negative mental states in common daily situations of their own choosing. The theory describes a mental "bridge technique" consisting of speaking self-regulatory verbalizations that counteract the negative emotions and thoughts. A key aspect of the self-change technique is to view one's mental state as comprising three distinct domains of experience and activity: affective, cognitive, and sensorimotor. This is called the "threefold-self". Success in crossing the bridge from negative to positive thoughts and emotions depends on engaging all three domains. Several samples are given to show how the students related to the theory and the task. All students were able to understand and follow the theory and selfmodification procedures. Student reports indicated acceptance of the theory and enthusiasm at the effectiveness of the approach. Additional research is needed to determine how long the change lasts.
\end{abstract}

Keywords: self-change, self-report, emotions, affective, cognitive
Volume I Issue I - 2014

Leon James

Department of Psychology, University of Hawaii, USA

Correspondence: Leon James, Department of Psychology, University of Hawaii, 2430Campus Road Honolulu, HI 96822 USA, Email leon@hawaii.edu

Received: May 0I, 2014 | Published: May 24, 2014

\section{Introduction}

There is a long history of research involving the content analysis of people's verbalizations as an index of their cognitive and affective processes in thinking and problem solving. ${ }^{1-4}$ Ericsson and Simon $^{5}$ recorded the verbalizations of subjects while they were doing problem-solving tasks with the think aloud method. Vygotsky ${ }^{6}$ focused specifically on the control function of children's inner speech. Meichenbaum, ${ }^{7}$ Ellis, ${ }^{8}$ Watson and Tharp ${ }^{9}$ focused on the use of self-regulatory sentences in self-modification attempts. James and $\mathrm{Nahl}^{10,11}$ ordered user discourse in self-reports into a classification of discourse produced by subjects while driving, while learning the library ${ }^{12}$ and while navigating the Internet. ${ }^{13}$ Labov and Fanshel ${ }^{14}$ chart the course of psychotherapy through speech act analysis of transcripts produced during the successful treatment of a bulimic patient. Speech acts were defined by Searle ${ }^{15}$ and Austin ${ }^{16}$ as normative verbal responses to a common social stimulus.

This article describes how the concept of the "threefold-self" was applied to assist individuals in their class self-modification projects regarding negative emotions in ordinary situations in their lives. The threefold-self was used previously to help drivers monitor their "driving personality" for the purpose of reducing their negative verbalizations in traffic. ${ }^{17}$ Another application was to assist individuals in reducing their mental resistance to health behaviors and thereby to increase compliance. ${ }^{18}$ Another application of the threefoldself involved defining and measuring the online skills and errors of students while learning to navigate the internet. ${ }^{12}$

These applications have shown that people are able to monitor many events going on in their mental life. When the threefold-self is explained to students they readily show the ability of observing and distinguishing the three major elements of their mental experience. These are known traditionally as the affective domain, ${ }^{19}$ the cognitive domain, ${ }^{20}$ and the sensorimotor or psychomotor domain. ${ }^{21}$ College students are normally able to write down in any daily situation what they are feeling (positive or negative affect), what they are thinking (cognitive behavior), and what they are sensing or doing (sensorimotor behavior).
If it is assumed that individuals can become aware of their thinking and feeling in daily situations, then it would seem beneficial to provide them with a general psychological theory that they can intuitively understand, accept, and apply to manage their mental and behavioral life. An attempt was made to present such a theory to college students in the form of written instructions for one of the optional class research projects. From their reports it became evident that the theory was simple enough, and general enough, to allow them to engage successfully in a self-monitoring project regarding their mental and behavioral reactions in ordinary situations of their choosing. The theory they were given to use is presented below. Afterwards an evaluation of their reports will be given.

The text of the following descriptions are based on the written project instructions in order to exhibit the language of the theory intended for college students majoring in psychology.

\section{Defining the threefold self}

This theory has two components: the idea of the "threefold-self" and the idea of a mental "bridge" that can be crossed to change from negative to positive states. The key idea of this theory is that the bridge can be crossed only when the three components of the self (affective, cognitive, and sensorimotor) act conjointly. Since feelings, emotions, thoughts, and actions are for the most part learned habits, it is possible to modify our feelings, thoughts, and actions and to replace them with new habits.

All individuals are socialized in accordance with cultural norms. To be socialized means to acquire particular habits in the three prominent areas of human functioning:

- Habits of feeling (affective domain of behavior)

- Habits of thinking (cognitive domain of behavior)

- Habits of sensing and acting (sensorimotor domain of behavior)

Every individual has a threefold-self in which the three domains of behavior act together, yet each can be distinguished and isolated for observation and self-modification. From the perspective of the 
individual, the threefold-self has two life arenas to function in. One is the arena of others and the world, and the other is the arena of self (the private world within). These two life arenas (others vs. self) each require their own particular way of functioning. Everyone needs to function in both arenas every hour of every day since we have to deal with others and the world (environment), as well as with ourselves.

Functioning in these two life arenas (others vs. self) can be negative or positive, healthy or unhealthy, self-enhancing or selfdestructive. People ordinarily evaluate their situation as positive or negative or some combination thereof (e.g. "How are you doing?"). It is common to consider positive feelings and thoughts as being more desirable than negative feelings and thoughts. Success, comfort, hope, and happiness are generally considered desirable, enhancing, and positive, while failure, hopelessness, discomfort, rejection are generally considered negative and undesirable.

\section{The four options in daily life}

Here is a conceptual diagram (Figure 1) that anyone can use to help organize the details of daily situations. The diagram depicts four "options" that are available in any particular situation. Every mental state will have three distinct mental components that are acting top down: affective (involving feelings and emotions), cognitive (involving thoughts and conclusions), and sensorimotor (involving sensations and overt actions).

The idea in a nutshell is for you to observe for a week your threefold-self at certain challenging times that you select during each day, and to observe the negative options that you are choosing in that situation. This is sometimes called "baseline observation week". The second part is called "intervention week" and consists of your conscious attempt to modify your ongoing negative state by crossing one of the two bridges leading to the positive side. This involves talking yourself into switching over from the current option you are using, which is negative, to the positive that is also available to you.

To study the diagram, consider the mental state depicted in the top left, "negative about others and the world." In this disturbing state the threefold-self is following a script and running off the habit routine known to people as rage, anger, arrogance (in the sense of belittling others), hostile, and so on. This negative affective feeling state or motivation in your mind seeks and hooks up with a type of cognitive thinking that is called emotionally biased or impaired because the judgment or cognitive logic is faulty. When we are in an enraged, arrogant, or hostile affective feeling state, there is a compatible cognitive thinking routine that is occasioned in our mind by the feeling state. If you critically examine this type of cognitive routine you will find that it is not objective, evidential, or rational but is merely made up to suit the negative feeling of rage, arrogance, or hostility against others. The negative emotion and the impaired thinking then combine together to produce an overt behavioral routine that is called aggressive or destructive behavior. In this way the threefold-self runs off a series of negative habit routines consisting of a negative feeling coupled with impaired thinking and acted out as destructive behavior. This is one option we habitually run off in many situations in which we find ourselves every day.

Now consider the option at the top right: "positive about others and the world." Here the threefold-self is running off the habit routine of resolve with compassion. This affective feeling state or motivation occasions and hooks up with a type of cognitive thinking routine that is called emotionally intelligent. When we are in a positive affective state of resolve with compassion, we are highly motivated to do something to solve a problem. The affective feeling habit of resolve (or determination) needs to be associated with the affective feeling habit of compassion. This is what makes it contrastive with rage. When we choose the rage option, all sorts of other related negative affective feeling habits will come associated with it, such as cruelty, hatred, and social insensitivity. But the resolve with compassion option comes associated with positive feeling habits such as compassion, empathy, respect, fairness, and tolerance.

The positive affective feeling state seeks out and triggers a compatible cognitive thinking habit. This type of cognitive thinking activity in the mind tends to be objective, evidential, and rational. We then understand the realities of the actual situation instead of misunderstanding it and replacing it with the subjective distortions in thinking caused by negative emotions. The positive affective feeling state of resolve with compassion then seeks out and combines with emotionally intelligent thinking, and together they produce an overt behavioral routine that is called supportive and constructive behavior. The threefold self runs off a series of positive habits consisting of a positive feeling coupled with emotionally intelligent thinking and acted out as constructive behavior. This is a second option.

The blue bridge connects the negative and positive portions of the lower half of the diagram. The bridge is shown to connect negative thinking to positive thinking because we have voluntary control over our thinking process, and much less control directly over our feelings. The idea of this approach is that if you voluntarily change your negative thinking into positive thinking--a choice we always can make--then the negative feeling will soon turn into positive. Then the new positive feeling coupled with the positive thinking together will produce the new overt behavior that is positive. At that point you're living the new option and you've been successful in crossing the blue bridge and switching over from the negative option.

Of course this may not last long since a few minutes later a new situation or concern comes along and we can be thrown back into the negative option. But now we can use the bridge technique again and get ourselves moving in the positive arena. Eventually, with daily practice, we will learn to switch to positive as soon as we observe ourselves being in negative mode. In this way we cumulatively change our life and our personality for the better. The bridge technique gives us a choice to customize our options to suit what's best for society and us.

You use the red bridge to cross from negative thinking about others to positive thinking, that is, from emotionally impaired thinking to emotionally intelligent thinking. Our ability to use the bridge technique is part of the socialization process that produces all our habits. The red bridge is crossed by talking to ourselves in a certain way so that we stop thinking negatively about someone or some situation, and start thinking positively. We have the capacity to monitor our thinking and to note that it is emotionally impaired or biased. We can then replace this type of negative thinking routine with more objective and emotionally intelligent thinking routines. Of course to use the bridge we must be motivated to use the positive option that is available. Without that motivation we keep re-running or re-cycling the negative routines of the threefold-self that we have acquired in the past.

The red bridge connects the negative and positive portions of the upper half of the diagram. Now look at the third option of routines that is labeled "negative about the self" (at the bottom left). A general name for that category is depression or feelings of inadequacy and lack 
of self-confidence. These associated negative feelings about ourselves seek out and encourage thinking routines that are called pessimistic or cynical. Feelings of depression are actually feelings of rage turned against our own self. Similarly, feelings of inadequacy are actually feelings of arrogance turned against our own self.

The fourth option is located at the bottom right of the diagram. It is labeled "positive about self." In this state we are opting for feelings of enthusiasm and self-confidence which we have available due to our socialization process. These positive feeling states would not last on their own because they need to seek out and be connected with positive thinking habits called optimistic and realistic thinking. The positive feeling states of enthusiasm and self-confidence act together with the positive thinking routines called optimism and realism, to produce the positive outward routines called self-enhancing behavior. The healthy growth of our personality and character depends on our choosing this fourth option. Self-enhancing behavior includes mental health, discipline, orderliness, mastery, and coping. The well-adjusted, happy, and successful individual chooses this option more than the negative counterpart.

As we make ourselves think positive things about ourselves (crossing the blue bridge), the positive feelings that are lying dormant (enthusiasm, self-confidence) will activate themselves since now they can conjoin with positive thinking routines that were not available before. When we make ourselves think optimistically and realistically we create the conditions for occasioning positive feeling routines such as enthusiasm and self-confidence. In other words, self-enhancing behavior will be the result when positive feelings of enthusiasm and self-confidence combine together with positive thinking called optimism and realism.

Your task in this project will be to monitor the negative options you tend to automatically select in particular recurrent situations every day, and then to use the appropriate bridge technique to switch to a positive zone. You will then observe to what extent the bridge technique worked out or not. Often we seem unable to cross the bridge due to the grip of negative feeling and thinking routines that appear to hold us there captive, and we seem to ourselves unable to get free of them. But at other times we succeed in crossing the bridge and changing the option that our threefold-self is performing. Your selfanalysis data will indicate when you are more successful and when you are less so. This is the purpose of the project.

What follows below further describes and explains the differences between the four options. The better you can understand these differences, the more accurately you can do this project and the more meaningfully you can write up your report. So it's important to reread and study these instructions several times until you are able to memorize most of the material.

Further Instructions on Self-modification of a Negative Emotion. You need to consciously modify all three elements of your rage. You modify your sensorimotor behavior first. Fix your face and your stance, stop gripping or fisting, relax your body and regain control over your breathing and voice. This may take a minute or two. In the meantime you need to focus on the cognitive and affective domains. Be sure to continue the self-modification process of your sensorimotor behavior and not interrupt it while you're throwing your focus over to your cognitive domain.

You modify your cognitive behavior by interrupting the thinking routines circling in your mind. You do this by contradicting and interrupting the rage or depression thoughts. Often these rage thoughts sequence themselves in series, and then recycle. We are familiar with it when we are venting, or someone we listen to is venting. It involves reasoning in a way that makes you right and the others wrong. Over and over again, almost like an obsession. This must be contradicted and interrupted.

You modify your affective behavior by invoking a higher affect or motive. All our affective behaviors or feelings are arranged in a hierarchy of domination. Our highest, deepest, or strongest affections dominate the lesser affections. The only way to control a passion or motive is by means of a higher or stronger passion. Ask yourself: What are my highest goals in this situation? You will find that it is not complaining or retaliating, but rather to stay safe and calm.

The diagram (Figure 2) summarizes what was said above about "the negative spin cycle." After looking at it, see if you can reproduce it from memory by drawing it on a piece of paper.

Note the one-way horizontal arrows showing the sequence of habits in the threefold self: the negative feeling states motivate you to select negative thinking sequences, and the two together produce the outward negative behaviors. The two-way vertical arrow on the left portrays the negative spin cycle that flip-flops between feelings about others, followed by similar feelings about the self, and then, recycling both ways keeping you in the negative zones.

\section{Self-regulatory prompts for crossing the red bridge}

The red bridge promotes productivity and leadership. As the diagram shows (Figure 3), it consists in bringing up thoughts that are incompatible with emotionally impaired thinking. For example, you might become aware that you're thinking, "He doesn't deserve my respect. I'm not going to get along with him." as this person makes a suggestion to you. You're thinking of all sorts of denigrating things you can do to him as a way of pursuing your dislike for this individual. But then you decide to apply the red bridge technique to combat your biased and hostile thoughts. From your memory you can bring up several favorable things about this person. The moment you convince yourself that you have no data to the contrary and that your hostile attitude is not justified, you're feeling state may change from negative to positive, from feeling hatred or anger (negative towards others, top left) to feeling resolve with compassion (positive towards others, top right). You tell yourself you're going to make the effort and see if this person deserves your compassion and good will rather than just assume he doesn't. Already you might feel better as a result of the flip-flop cycle from positive toward others to positive toward self. Crossing the red bridge (positive towards others) promotes crossing the blue bridge (positive towards self).

To cross the red bridge in your mind (top half) you need to say to yourself appropriate self-regulatory sentences. You can prepare them ahead of time and write them on a reminder sheet.

Here are some self-regulatory prompts for crossing the red bridge. You can say them to yourself to strengthen your determination to do something constructive (resolve with compassion--option 2) rather than to remain in the destructive rage mode (option 1)--see if you can memorize them:

**Order yourself to stop ruminating (=the compulsive rehearsal of how you're going to get even and retaliate) **Question your cold logic or negative conclusion by qualifying it, saying to yourself: "Not necessarily" or "Maybe, maybe not". This helps weaken the intensity of your negative persuasion. 
**Make yourself think of relevant counter-information that you've been ignoring so far

** Restore balance by reminding yourself to think of both sides of the issue

** Figure out a more effective course of action

** Act the opposite of what you feel and say nice things instead of not nice

** etc.

(Note: All the lists in the written project instructions to students were more extensive than shown in this article).
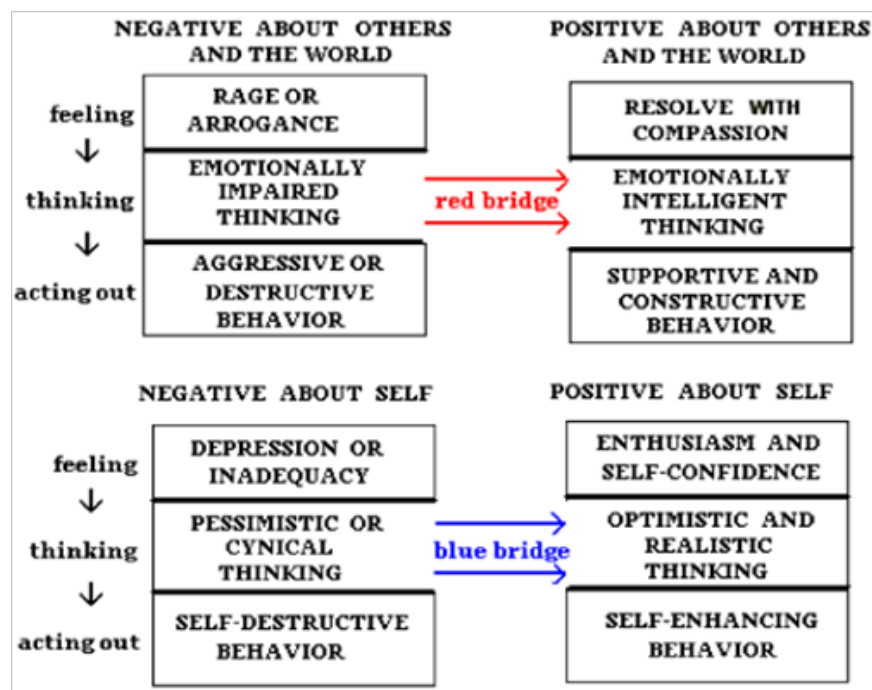

\section{The Four Options}

On the Daily Emotional Spin Cycle

And the Two Bridges

Figure I The four options.

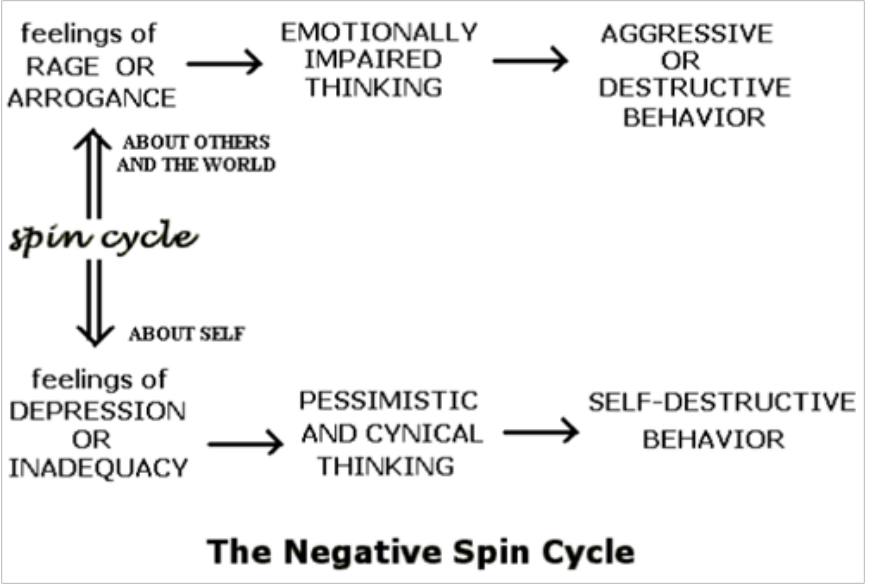

Figure 2 The negative spin cycle.

\section{Self-regulatory prompts for the blue bridge}

Here are examples of prompts you can use to create resistance to pessimism or cynicism, and to facilitate the opposite type: optimistic and realistic thoughts:

**Question your assumptions that lead to negative conclusions
**Tell yourself "Stop it!" when you witness yourself ruminating compulsively

**Do a scenario analysis of the situation, writing down all the versions

**Do a re-appraisal of the situation and find some good things about it

**Tell yourself you're going to feel better about yourself by switching emotional style

**Reassure yourself that you are capable and review your accomplishments

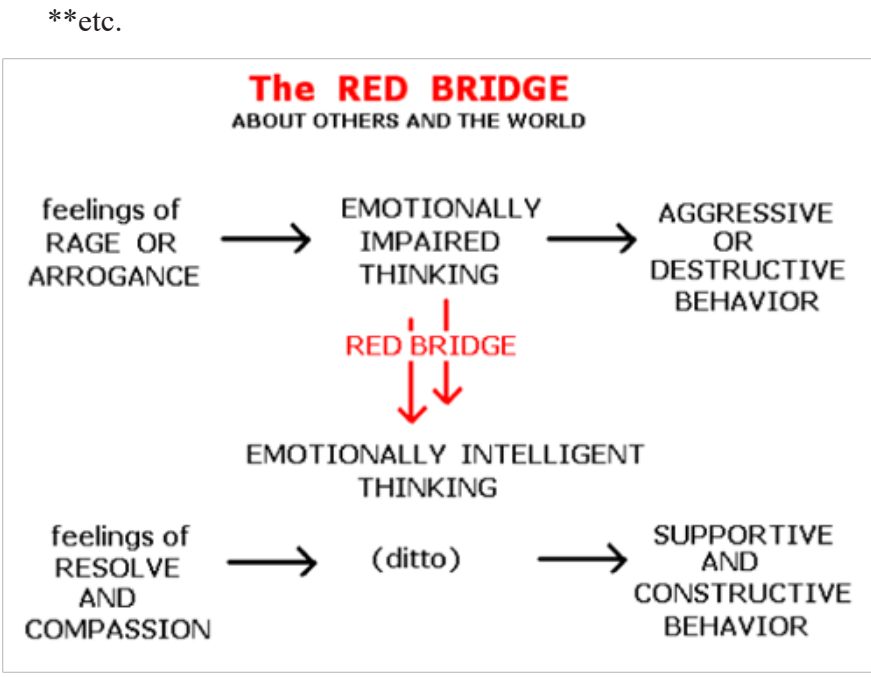

Figure 3 Crossing the red bridge.

Now let's take a look at the four options in detail to see how each actually consists of many habits that act together. By studying these lists you will be able to recognize and correctly categorize what your threefold self is doing in any situation you are observing. See if you can reproduce most of the lists from memory.

\section{Monitoring option I: negative towards others}

\section{Negative affect}

Negative affect or feelings against others can be summarized under the category of rage (anger) or arrogance. This refers to a desire or motive to hurt someone or to damage and destroy something. This emotional option includes a large collection of negative feeling habits towards others and the world such as: **Desire to harm or cause injury or loss to someone for the sake of vengeance

**Hatred or the desire to torture or kill someone, or to make them suffer

**Wanting to condemn someone as worthless or useless

**Wanting to discriminate against someone due to your prejudice

**Feeling like throwing something or punching out in blind fury

**Enjoying mocking someone or putting them down

**etc.

Make sure you have the main diagram of the four options pictured in your mind as you go through these lists. 


\section{Negative cognitions}

Negative cognitions or thoughts towards others are made of emotionally impaired thinking routines. This type of thinking process is often biased, inaccurate, and irrational. For example, we might assume that someone wanted to insult us when in fact there was no such intention. It's common to make mistakes and exaggerate when we think in this faulty manner. Emotionally impaired thinking is encouraged or facilitated by anger or arrogance. When you feel rage or disdain towards someone, you begin to think in an impaired fashion, making the wrong assessment of the situation, losing the sense of reality. Negative feelings and negative thoughts always function together and support each other. It's common to be aware of our thoughts but most people are less aware of their own feelings. This emotional option includes a large collection of negative thinking habits such as: **Planning to take revenge or to retaliate no matter what

**Engaging in fantasies of violence or torture

**Thinking about all the things you're going to say to upset or insult someone

**Compulsively going over and over again some past conflict situation

**Conveniently ignoring relevant information

**Exaggerating or being inaccurate in order to justify our rage or arrogance

$* *$ etc.

\section{Negative sensorimotor behavior}

Negative sensorimotor behavior does not occur by itself. It is preceded by negative feelings and thoughts. For instance, if you're feeling anger towards someone (option 1) and you become aware of negative thoughts, you frequently act out your anger by behaving aggressively or destructively. You may feel like being violent in some situation in which you feel rage and at the same time you think thoughts that justify and reinforce your anger. Since in many situations it is dangerous for us to express hatred and judgment in overt action, we have learned to inhibit the overt hostile doing, and so our rage remains private. Here are examples of negative doing (sensorimotor behavior): **Attacking someone in anger using your body, an object or weapon

**Standing in a hostile or aggressive pose to threaten someone

**Yelling at people to make them feel bad

**Speaking with a sarcastic tone to insult someone

**Gesturing insults or using offensive, mocking, or ridiculing language

**Making an irate phone call

**Damaging property to retaliate or get even

**Breaking your promise or commitment because you're mad

**etc.

\section{Positive red feelings (affective)}

Positive red feelings (upper right half of diagram) are perfect substitutes for negative red feelings. All red feelings are "hot" or intense and powerful, but it makes a difference if they are negative hot or positive hot. Negative red-hot feelings are associated with rage or arrogance (option 1). Positive red-hot feelings are associated with resolve and compassion (option 2). Resolve, or determination, is an intense motivation for protecting something valuable to society, like a cause or principle you feel strongly about.

For instance, instead of complaining and getting mad, you decide to do something practical to change a public situation. Sometimes the feeling of resolve appears to others as anger, but it's not. For instance, anger (or rage) is the strong desire to punish, destroy or injure by an aggressive act, whereas resolve with compassion is the strong desire to protect or support something by democratic or humanitarian means provided by law and conscience. The feeling of compassion has to be added to resolve so that you don't fall back on blind anger. Compassion is a feeling of support for someone who needs help. It is the desire to assist, rescue, and protect what we consider valuable or loved. The feeling of compassion includes the fear to injure someone, and so it is the opposite of anger (the desire to hurt someone). Resolve combined with compassion (option 2) is the perfect antidote to anger and rage (option 1).

Here are examples that can help you better observe and describe your feelings that fall in option 2, called resolve with compassion.

**Rejecting your impulse to be violent or to injure someone or something

**Promoting in yourself the feeling of compassion

**Promoting in yourself the desire for peace or the desire to forget and forgive

**Honoring your commitment to do something constructive and avoid conflict

**Seeing the humor of your predicament and laughing at the whole thing

**Feeling sympathy or caring for the other person as a human being

**Feeling good about being fair-minded and civilized

**etc.

\section{Positive red thinking (cognitive)}

Positive red thinking has to be compatible with positive red feeling and the two mutually support and reinforce one another. Positive red thinking is the opposite of negative red thinking and can be used to counteract it. This is called applying the red bridge technique. The negative and positive thinking are incompatible and cannot exist simultaneously in our mind with the same force so that one wins and inhibits or suppresses the other. When the negative thinking is strong or pervasive in our mind, the positive is weakened and stays in the background, rendered ineffective for now. This is called seeing red-which refers to impaired thinking due to negative emotions.

We have the ability, from a higher motivation of self-interest and conscience, to perform positive thinking routines in order to counteract the negative thinking routine we are performing in some particular situation. Emotionally impaired thoughts (option 1) are personal, skewed, anti-social, inaccurate, and unrealistic, while emotionally intelligent thoughts (option 2) are pro-social, objective, realistic, and accurate. Emotionally intelligent thoughts include stopping your negative thinking routines and making yourself run off positive thinking routines such as considering better alternatives you have in a situation, and their positive outcomes. These positive thoughts interact and reinforce positive feeling routines. 
Table I Gender differences in self-reports of daily emotions

\begin{tabular}{|c|c|c|c|}
\hline \multirow{2}{*}{$\begin{array}{l}\text { Survey Items } \\
\text { ("How often do you feel that emotion") }\end{array}$} & \multicolumn{2}{|c|}{$\begin{array}{l}\text { Combined } \\
\text { Percent for Dailyl } \\
\text { Hourly }\end{array}$} & \multirow[t]{2}{*}{$\begin{array}{l}\text { Chi Sq. and } P \\
\text { value }\end{array}$} \\
\hline & Men & Women & \\
\hline \multirow[t]{2}{*}{ How often do you experience anger, rage, or hate? } & 40 & 31 & $13.60 * *$ \\
\hline & & & 0.0035 \\
\hline \multirow[t]{2}{*}{ How often do you experience enjoying fantasies of violence? } & 15 & 5 & $60.86 * *$ \\
\hline & & & 0.0001 \\
\hline \multirow[t]{2}{*}{ How often do you experience feeling like being rude, obnoxious or sarcastic to someone? } & 45 & 35 & $10.87 * *$ \\
\hline & & & 0.0125 \\
\hline \multirow[t]{2}{*}{ How often do you experience feeling criticized, picked on or bullied? } & 13 & 16 & $8.36 *$ \\
\hline & & & 0.0391 \\
\hline \multirow[t]{2}{*}{ How often do you experience feeling discouraged or depressed? } & 26 & 28 & $9.23 *$ \\
\hline & & & 0.0264 \\
\hline \multirow[t]{2}{*}{$\begin{array}{l}\text { How often do you experience feeling that something must be wrong with you, that you are incompetent, } \\
\text { inadequate, and defective? }\end{array}$} & 18 & 20 & $10.66 * *$ \\
\hline & & & 0.0137 \\
\hline \multirow[t]{2}{*}{ How often do you experience expecting the worst, constantly fearful of what might happen, pessimistic? } & 24 & 20 & $12.08 * *$ \\
\hline & & & $0.007 \mid$ \\
\hline \multirow[t]{2}{*}{ How often do you experience excessive sorrow, grief, guilt, self-blame? } & 12 & 9 & $10.93 * *$ \\
\hline & & & 0.0121 \\
\hline \multirow[t]{2}{*}{ How often do you experience ruminating, exaggerating, sulking? } & 12 & 7 & $9.55^{*}$ \\
\hline & & & 0.0228 \\
\hline \multirow[t]{2}{*}{ How often do you experience feeling angry because someone tries to stop you from doing what you want? } & 18 & 12 & $13.07 * *$ \\
\hline & & & 0.0045 \\
\hline \multirow[t]{2}{*}{ How often do you experience feeling angry because someone hurts your feelings? } & II & 14 & $18.58 * *$ \\
\hline & & & 0.0003 \\
\hline
\end{tabular}

Table 2 First day of intervention trials

\begin{tabular}{lll}
\hline Rating Scale & First Day of Baseline & First Day of Intervention \\
\hline I=very weak; I0=extreme & 10 & 7 \\
\hline What was my overall stress point today & 8 & 8 \\
\hline What was my overall level of satisfaction with myself today & 8 & 6 \\
\hline What was my overall level of dissatisfaction with others today & 7 & 8 \\
\hline What was my overall level of effectiveness or productivity today & 4 & 8 \\
\hline What was my overall level of coping successfully with my feelings today & 8 & 10 \\
\hline What is my current level of hope for the future & 10 & 10 \\
\hline What was the worst level of negativity or selfishness & & \\
\hline of some other people around you & & \\
\hline
\end{tabular}

\section{Positive red doing (sensorimotor)}

Positive red doing is to act in a supportive and constructive manner. This is the sensorimotor outcome of positive feeling and positive thinking acting together. Feelings of resolve with compassion seek out and encourage emotionally intelligent thinking routines, and the two together produce constructive and supportive behaviors such as cooperation, friendship, and sharing. Examples include: **Keeping your voice down and acting with civility

**Speaking with a neutral tone that would not be considered aggressive

**Finding something good to say, counteracting the negative

**Showing patience and being accommodating

**Keeping a pleasant expression on your face

**Removing any insult, sarcasm, or condemnation when writing a letter or note

**Leaving only polite and reasoned messages for others
**Keeping your promise or commitment even if you're upset

**etc.

\section{The blue zone}

The blue zone refers to the emotional lifestyle we have towards ourselves (bottom half of the four options diagram). There is a negative blue zone (option 3 ) and a positive blue zone (option 4). Depression or inadequacy is the title for a group of negative feelings towards oneself. Depression or feelings of inadequacy are forms of raging against oneself. It includes dissatisfaction that becomes obsessive, also generalized anxiety and excessive worry. Pessimism is a type of thinking that involves unrealistic and exaggerated expectations of negative outcomes in our undertakings. Cynicism is a type of thinking that involves automatic suspicions and doubts regarding sincerity, goodness, and truth in ourselves (and in people generally). Pessimistic and cynical thinking routines are encouraged and strengthened by negative feelings towards the self such as depression, inadequacy, chronic dissatisfaction, excessive worry, hopelessness, and helplessness. 
Table 3 Appendix: Example of ANOVA Analyses

\begin{tabular}{ll}
\hline $\begin{array}{l}\text { Summary table for interfer } \\
\text { Gender I. }\end{array}$ & $\mathrm{I} 2$ \\
\hline Num. Missing & 3 \\
DF & 13.066 \\
Chi Square & 0.0045 \\
Chi Square P-Value & 13.253 \\
G-Squared & $0.004 \mathrm{I}$ \\
G-Squared P-Value & 0.105 \\
Contingency Coef. & 0.106 \\
Cramer's V &
\end{tabular}

Observed frequencies for interfered 34, Gender I.

\begin{tabular}{llll}
\hline & Female & Male & Totals \\
\hline Daily & 61 & 78 & 139 \\
Hourly & 11 & 26 & 37 \\
Rarely or never & 358 & 311 & 669 \\
Weekly & 148 & 171 & 319 \\
Totals & 578 & 586 & 1164
\end{tabular}

Percents of row tables for interfered 34, Gender I.

\begin{tabular}{llll}
\hline & Female & Male & Totals \\
\hline Daily & 43.885 & 56.115 & 100 \\
Hourly & 29.73 & 70.27 & 100 \\
Rarely or never & 53.513 & 46.487 & 100 \\
Weekly & 46.395 & 53.605 & 100 \\
Totals & 49.656 & 50.344 & 100
\end{tabular}

Percents of columns tables for interfered 34, Gender I.

\begin{tabular}{llll}
\hline & Female & Male & Totals \\
\hline Daily & 10.554 & $13.31 \mathrm{I}$ & 11.942 \\
Hourly & 1.903 & 4.437 & 3.179 \\
Rarely or never & 61.938 & 53.072 & 57.474 \\
Weekly & 25.606 & 29.181 & 27.405 \\
Totals & 100 & 100 & 100 \\
\hline
\end{tabular}

\section{Negative blue feelings}

Negative blue feelings are experienced in many varieties that include self-hatred ("I hate myself"), desire to punish self ("I'm such fool. I could kick myself"), feeling guilty ("How could I do such a thing"), ashamed ("Oh, no, what are they going to think of me"), lack of enthusiasm ("Everything sucks"), and so on. Here are some examples that can help you better witness and describe your feelings in option 3 titled depressions and inadequacy--see if you can memorize them:

$$
\begin{aligned}
& \text { **Feeling mad at yourself (calling yourself negative names) } \\
& * * \text { Wanting to hit or kick yourself (raging against oneself) } \\
& \text { **Feeling helpless } \\
& * * \text { Feeling over-anxious or terrified about a normal event } \\
& * * \text { Feeling totally discouraged and unable to stop }
\end{aligned}
$$

**Feeling picked on all the time (without objective evidence)

**Ignoring health motives, letting yourself go

**Ignoring prudence, showing preference for high risk behaviors

**etc.

Negative cognitions about self

Negative cognitions about self are characteristically pessimistic or cynical. Pessimistic thinking includes catastrophizing, which is the tendency to expect the worst to happen to us in some situation and to magnify or exaggerate the likely negative consequences. Cynical thinking is a kind of pessimism since it suggests that nothing is fair, noble, or sincere in what we do, or what anyone else is doing. Feeling depressed or obsessively dissatisfied engenders pessimistic and cynical thoughts. The feeling and the thinking agree with each other and end up on the same side, reinforcing one another and strengthening their bond. Together they can produce negative forms of acting out called self-destructive behavior. Here are examples that can help you better witness and describe your pessimistic and cynical thinking routines:

**Thinking that the worst is going to happen or catastrophizing

**Compulsively thinking about bad things (ruminating)

**Blocking out what others are saying or suggesting (skewed thinking)

**Ruminating over something that happened and unwilling to stop thinking or talking about it

**Thinking cynically and doubting anything good and true

**Deciding there is nothing you can do about something (helplessness)

**Thinking you don't deserve better (low self-esteem)

**etc.

\section{Self-destructive behavior}

Self-destructive behavior is the overt outcome of combining negative feeling and thinking (option 3 ). The variety of such behaviors is quite large and they are familiar to everyone. They include loss of energy and motivation, the slowing down of the body, reduced activity and productivity, so that we fail to complete tasks or we deliberately make errors to sabotage the outcome, thus insuring that we lose. We also tend to engage in high-risk behavior that is dangerous and destructive to ourselves. This negative sensorimotor behavior continues as long as the negative feeling and thinking continue to act together. In other words, as long as you continue to feel obsessed with your dissatisfaction and reinforce this feeling with pessimistic or cynical thoughts, you will act out some self-destructive behavior. Here are examples that to help you better witness and describe selfdestructive behavior routines:

\footnotetext{
**Moving abnormally slow or feeling tired all the time

**Unable to complete tasks

**Sustaining injuries due to carelessness

**Engaging in high risk behaviors due to recklessness

**Looking downcast, unhappy, discouraged, sad sack

**Doing dangerous and reckless things that are out of control

**etc.
} 


\section{Positive blue feeling towards self}

Positive blue feeling towards self typically includes the feeling of self-satisfaction, self-mastery, and the desire to enhance your potential. It's the opposite of negative blue feeling. Positive blue feelings seek out and promote positive blue thinking routines. Positive blue feelings also function to counteract negative blue feelings so you feel less depression or dissatisfaction, if any. Positive feelings towards self include feeling enthusiastic, effective, productive, grateful or appreciative, and feeling more integrated and whole. **Feeling satisfied with your work

$$
\begin{aligned}
& \text { **Feeling confident you'll succeed } \\
& \text { **Having a "Can Do" attitude } \\
& \text { **Not being afraid to stand up and be counted } \\
& \text { **Being motivated to improve yourself } \\
& \text { **Being motivated to maintain a healthy lifestyle } \\
& \text { **Being committed to uphold your beliefs and values } \\
& \text { **etc. }
\end{aligned}
$$

\section{Positive blue cognitions}

Positive blue cognitions are optimistic as well as realistic. They are compatible with positive blue feelings such as the feeling of self-mastery and self-confidence. Optimistic thinking counteracts pessimistic thinking, and instead of expecting the worst, one ranks the possible or likely outcomes of any event in terms of their probability or likelihood of happening. Positive thinking is not only optimistic but realistic, objective, and rational. Switching into positive thinking about self is called the blue bridge technique. Some illustrations: **Thinking about what is likely to happen instead of what one fears

\section{**Questioning your pessimism and cynicism}

**Making yourself stop thinking about something negative

**Deliberately trying to figure something out instead of jumping to conclusions

$$
\begin{aligned}
& * * \text { Examining what others are saying about your situation } \\
& * * \text { Thinking that with practice you can achieve your goal } \\
& * * \text { etc. }
\end{aligned}
$$

\section{Positive sensorimotor behaviors}

Positive sensorimotor behaviors include a variety of self-enhancing routines such as:

**Following regular and lifelong healthy diet and exercise programs

\footnotetext{
**Acting with discipline leading to your goals

**Maintaining good relations with others

**Doing things that lead to success

**Practicing good time-management techniques

**Maintaining a neat or appropriate appearance

**Taking steps to protect what's yours

**etc.
}

\section{Design of your project}

\section{Week 1: Baseline observations}

Sample negative red activity A (negative towards others):

day 1 || day 2 || day 3

Sample negative blue activity B (negative towards self):

day 4 || day 5 || day 6 blue)

Week 2: Intervention--practicing the bridge technique (red and

Sample positive red activity A again (positive towards others)

day 1 || day $2 \|$ day 3

Sample positive blue activity B again (positive towards self)

day 4 || day 5 || day 6

The purpose of the project is to enable you to monitor the negative spin cycle options that you choose in some of your recurrent daily activities, and then to use the bridge technique to move your spin cycle from negative to positive options.

You need to select an activity that you do on three consecutive days every week--so this limits the choices. Examples include: Getting up in the morning; doing things at home (cleaning, fixing, cooking, etc.); driving to work or school; performing your job tasks; going shopping; talking to someone on the phone; watching a particular TV program; studying or doing your homework; and other such recurrent activities you do alone or in company. The activity could be short (just a few minutes) or long (several hours), but it must be recurrent or routine so you have to face the same psychological issues every day.

At the same time, the activity you select must have elements that fall in the negative category (options 1 and 3, left side of diagram). One sample involves an activity in which you feel, think, or do something negative towards others and the world (negative red-option 1). Another sample should involve option 3: negative towards the self (negative blue). So you need to select a daily recurrent activity during which you can observe yourself run off negative routines towards others (red) and self (blue). Activity A must be negative towards others and the world (negative red) while activity B must be negative towards the self (negative blue).

You start with sample activity A on day 1 . You need to take notes of your actual feelings, thoughts, and doings or use a voice recorder to dictate them. Be sure you end up with enough of a sample of what you are actually feeling, thinking, and doing in the selected situation. You also need to explain the context so the activity makes sense to the reader.

\section{To monitor what you are feeling}

Ask yourself: What am I feeling right now? What do I feel like doing right now? Usually you get an inkling of what it is and then you can describe it: e.g., I feel like walking out; or, I feel like smashing something; or, I feel I'm being denigrated; I feel totally hopeless; etc. Keep writing things down as long as that feeling lasts--seconds, minutes, or hours. Be sure you distinguish between what you are feeling and what you are thinking. Sometimes we need to use a metaphor to describe what we are feeling. There may be several ways of describing a sequence of negative feelings. Be sure to study the lists given for options 1 and 3 to help you observe the negative feelings. 


\section{To monitor what you are thinking}

We think many sentences in any situation in a brief period of time. Try to write down as many sentences as you can or is feasible in the situation. Be sure to study the lists given for options 1 and 3 to help you observe the negative thinking.

\section{To monitor your sensorimotor doing}

First separate what is invisible to others and what is visible. Ask yourself: What am I sensing in my body? Invisible sensorimotor routines that are negative include sensations of weakness or tension, pain or unpleasantness, heat or cold, and so on (see lists above). Then ask yourself: What can others see about me? Visible sensorimotor routines that are negative include what others can detect from your voice, choice of words, face, hands, gestures, posture, appearance of your clothing, smell, etc. Be sure to study the lists given for options 1 and 3 to help you observe the negative doing.

When you finish the first day with activity A, you repeat the process for day 2 with the same activity, and finally, the third day. Then you begin observations with activity B on day 4 , and repeat for day 5 and 6 . This is the end of your baseline observations--two activities observed on three different days each (see design above).

Now you begin your intervention week, doing the same thing as before. The only difference is that now you are going to apply the bridge technique.

You stick with the same two activities but now you are introducing the intervention we called the bridge technique in the discussions above. This time it's important to keep notes on how you use the bridge technique in addition to the feeling, thinking, and doing (as you did the first week). Write down what you actually said to yourself to move yourself over from the negative to the positive options, either red or blue. Then describe the consequences of applying the bridge technique: What was your feeling after crossing the bridge? What was your thinking? What was your sensing and doing? These consequences may be immediate or longer lasting. Or, the bridge technique may not work out or may end up having no visible effect.

\section{Evaluating the approach}

Two issues come up in the evaluation of the reports written by the participating students. First, were they able to perform the steps of the project as defined in the written instructions? All 17 students who chose to do the report were able to perform the entire series of steps. Second, did they find the procedure helpful or useful for their personal goals? All students expressed enthusiasm regarding how well the bridge technique worked for them on those occasions they tried it. A few representative sample paragraphs from 6 different students are reproduced below to show how the students related to the project.

\section{Sample I}

Tonight my boyfriend and I celebrated his birthday; I took him out to dinner at Ryan's. Of course we were talking and my boyfriend started making comments about things I said and things I did. I usually get really mad and throw it all back to him, but used the blue bridge and resisted feelings I had to retaliate and argue with him. I told myself to "stop it" and "calm down." It worked really well, I was able to make it through the evening without any fighting or disagreeing, at least on my part. I felt much calmer, like I was able to handle the situation more effectively by using the bridge. My respiration was normal and I didn't feel any increase in heart rate.
Comments of this student: The stimuli that lead up to the occurrence of my spin cycles were sensations of fear, rage, frustration, anxiety, and discontentment. Sometimes people hanging around the door at the end class set me off, fighting with my boyfriend definitely caused rage and frustration, being in traffic and having people cut me off made me crazy. It was an endless amount of little things that I let drive me over the edge. I would go through the cycle all day everyday hiding it from myself. Although deep down inside I knew I was protecting myself and I didn't know how to handle my feelings and emotions. That's what kept my rage and anxiety up, my inability to accept what I was feeling and to deal with it. I assumed I could handle it all because I had been doing it the whole time, but I found out that, yeah I was handling my anger but not the right way.

(...) I tried using the bridge methods of crossing over from negative thinking to a positive outlook, but it was complicated. The one concept that jumped started my recovery were the self-regulatory sentences. When I started telling myself to stop it and calm down and maybe, maybe not, it helped to me stop and really ponders what I was feeling and why I felt that way. After I realized that I need to make a conscious effort to stop and think, it made all the difference recovery and modification were now possible.

(...) This report opened my eyes to my true emotions and feelings, some of which I didn't know existed until now. I feel I've gained a greater awareness of how to handle and cope with different situations, people, and emotions. I realized that coping with our emotions is vital if not crucial to how we live our lives every day; because everyone has feelings and they are what help them or discourage them through the span of the day. "

\section{Sample 2}

\section{When the Red Bridge Technique Worked}

I just got home from class and I am kind an irritated because one of my classes has a mandatory attendance policy and most of the time half the students in the class don't even show up. I go to class every single day, as I am supposed to but the students that don't attend class seem to be getting the same grade as me and I don't think that it is very fair. That makes me feel anger towards the teacher because they are not sticking to their policy (zone 1) but then again, maybe they are and just haven't totaled the other students attendance in with the rest of their overall grades. This made me a little less angry.

\section{When the Red Bridge Technique Didn't Work}

Tonight was a very good night up until I got into yet another fight with my boss. We were working at around 9:30 pm I took a break since I had not stopped busting my butt for about 2 hours. It didn't seem like they needed help, so when I realized that they did (no one said anything) I went to help my bosses and coworkers and my boss made this really snide remark to me and said "Only now you come to help when everything's done." She did not say it in a joking way and there were a lot of people around. Out of rage (zone 1) I reacted in a very negative way. I said "Kiss me a\%@" and she tried to play it off like she was only joking and I just replied "I wasn't" and walked away. I have to say though, although I reacted very negatively, it gave me satisfaction to let her know how I really felt. I know this is bad, and I tried to tell myself to just ignore it but I couldn't my rage got the best of me and my bridge technique just didn't work.

\section{When the Blue Bridge Technique Worked}

I've been doing homework for the past 4 hours and it seems like I haven't done anything! I am definitely in zone 1 and 2 of the emotional 
spin cycle because I can't figure out what to do for my assignments or am just not in the homework mood. I'm feeling rage because although I am trying to get things done, it is just not happening. I feel like going out and having fun and forgetting about homework. I know that I will regret it but right now I just don't care (zone 2). I know I will have to pay for it tomorrow but oh, well! Then, I thought, maybe I can go out and clear my mind for a while, and then tomorrow I can get on a role and finish my projects with a clear head. That made me move into zones 3 and 4 .

\section{When the Blue Bridge Technique Didn't Work}

I just got off the phone with a really good friend who I have known for 10 years and he has had a drug problem for the past 6 years. We always fight about this problem because I think that he is zone 2 of the emotional spin cycle because he is into self-destructive behavior. When I ask him why, it's because he says that he is in zone 3 and it makes him happy. When I hear this, I get angry with him and I get in zone 1 because I don't want to see him hurt himself like that and I have to admit, am trying to condemn him. We end up talking about it but nothing happens and he still continues to do this so we just end our conversation and usually make like nothing happened. But I'm not sure if that is constructive behavior (zone 4) because I'm depressed at myself for not stopping him, leaving me in zones $1 \& 2$. Then I went into zone 4 and thought okay maybe this is just a phase. But after serious consideration and worry, I don't think it is a phase. Realistically, he's been doing it for 6 years. A six-year phase?? I don't think so.

\section{Sample 3}

Comment by this student: The Bridge refers to the sentence I said to myself to convince myself to "cross the bridge" from the negative zone to the positive. The Bridge is supposed to initiate a new positive way of thinking to counteract the current negative thinking. But to start the Bridge I needed first to be motivated to change my thoughts. My motivation was to not let small and unimportant things destroy my marriage and my life. So every time I became aware of my negative feelings and thoughts I brought to my mind this sentence, which leads me to new, more rational thoughts, feelings and actions. The first couple times there was a big struggle to change to the new thoughts, but this struggle decreased with time.

I need to say that I learned a lot about myself doing this project. I now use the techniques described above in my day-to-day life, especially the Bridge technique. I used to be a very emotional person and reacted several times in very inappropriate, irrational ways, making myself and people around me miserable. Now, when I feel I am raging, I automatically become aware of my threefold self, I first analyze why I am feeling like that. This brings up my motives, making me realize the unimportance of the event, and soon I forget about it without spoiling my day (which used to happen constantly). I definitely recommended this technique to my friends (who are emotionally like I was) and I will keep doing it.

(...) Throughout this report I couldn't help to wonder if this modifying of my negative behavior to positive behavior was going to work and stay in a permanent atmosphere. I fear for the worse that this modification will not last for long. However, this self-witnessing project is a very good way to have those who are willing to change for the good of themselves. I feel that this concept of the emotional spin cycle and this project of witnessing our own negative emotions to try to change them towards the positive should be introduced to many other schools nationwide, maybe even worldwide. Who knows if individuals take a hold of their own emotions and come aware of them they could better relate to others around them in a more, caring, sensitive, understanding manner.

\section{Sample 4}

This evening I was feeling anger towards my son for not doing his homework at afterschool care. I thought, "Here we go again. Why is it so difficult for him to remember to do homework?" At this time I implemented the Red bridge. I thought to myself, "Relax. Getting angry hasn't accomplished anything before. Just have him get to work when he gets home and don't raise your voice when talking to him." I could feel the tension in my body because of being angry but I was successful at talking to him without raising my voice. I noticed that he seemed to concentrate a little more on his work and did get done quicker than usual.

Comment by this student: During week two, I used the red bridge to move myself from the negative side of the emotional spin cycle to the positive side of the cycle. I didn't want to keep getting angry with my son so I intervened during the thinking process to change my thinking to positive thinking. I was surprised at the results. I didn't think it would be that difficult to change my thinking to positive. The challenge was to be constantly aware of what is going on. It was very simple to forget because we are so conditioned to respond in certain ways to given situations. However, I was fairly successful in using the Red Bridge. I found that I was able to control my anger by not doing things such as raising my voice to my son. Instead, I remained calm and just reminded myself that yelling at him doesn't accomplish anything. The part that surprised me the most was the response from my son. I found that when I was on the positive side of my emotional spin cycle, my son was much more receptive to my help with his homework. He got his work done more quickly and paid more attention to me when I was helping him. I found that showing anger towards him had the opposite effect that I wanted. If I wanted him to do his work, I had to be positive in helping him. In reviewing my daily global ratings, I found that my overall stress level went down during week two and I was much more satisfied with myself. I felt better about myself because I had learned how I could control my anger toward my son. I have spent so much time feeling horrible about myself because of the way I treat my son. Now, I have a tool that I can use to improve our relationship.

\section{Sample 5}

Feeling- I feel very in control with my job at this moment. The kids have listening to me so far and I feel that I am in charge of the situation. I feel at ease with the children. - It is 3:00 pm and the children should be doing their homework right now, but I find them disobeying me. I feel frustrated with the kids, and I also feel rage building within me.

Thinking- "I want to tie this kid up with rope, maybe then will he settle down. - I feel "rigidified" as I ask a child to put his Pokemon cards away. He is not listening to me. - I usually scold this child, so I find that I scold him even more although he does not really do anything wrong.

Acting - I found that I made a sly face at one of the children out of disgust and then I sighed a deep sigh (not a sigh of relief, but a sigh of anger). - I told one of the kids "I don't care" when they asked about when they would get their Pokemon cards back.

The data from this table was taken from my borderline observations during week 1 of the experiment. This sample is representative of an activity in which I am negative towards others and the world. The 
activity that I chose was dealing with the stress at my job caused by the unruly children that I mentor.

Comment by this student: This project has allowed me to learn a tremendous amount about my tendencies when it comes to my emotions. I have come to understand why I do certain things and why I behave in certain ways. My thinking is the key to dealing with both my feelings and my sensorimotor actions. I have come to understand how I can adjust the way that I think in such a way that I change the way I behave and feel about myself, thereby allowing me to live a life that is so much more fulfilling.

When I began this project, I did not consider how I could succumb to such negative thinking. In fact, through this project, I have come to the realization that it is my negative thinking that does not allow me to strive forward; rather, it holds me back from being productive. The positive aspect, though, is that I do have the ability to change my thinking processes, if I so choose to. I found that strength of mine is the ability to change. If it were not for my ability to change my thinking, then I would not have had been successful at customizing my emotional spin cycle. Another strength is my ability to continually and consistently use the bridge technique throughout the day so that I am constantly customizing my emotional spin cycle to fit my needs.

\section{Sample 6}

Situation: Marvin (constantly picks on children who are smaller than himself, in other words, Marvin is a bully. Marvin began picking on this one boy, shoving him and even punching him, so I intervened. Although I am not supposed to, I told both of them to "shut up." After I intervened with their ensuing fight, I applied the bridge technique to the situation because I knew I was becoming upset.

Feeling- "I want to hit one of these kids because they are just so stubborn and do not want to listen at all."

Thinking- If I hit Marvin then he will shut up and not be troublesome. Once I began having these thoughts I applied the bridge technique. My new thinking was that if I hit Marvin then I would get sued. I will gain nothing by hitting Marvin but will probably get penalized for my actions.

\section{Sample 7}

Baseline Week: Negative about Others

Feeling: Angry, frustrated, pissed-off, aggravated, and overwhelmed.

Thinking: I'm taken advantage off; the Patrons are stupid, the task assigned is impossible.

\section{Summary}

Supervisor asked me to look for something missing in a large pile of items. Looking for hour and a half and not finding a thing, I began swearing and contemplating the "unfairness" of the task at hand. After searching, I returned to the front desk to help a patron. The patron was asking for help and I kept thinking she was 'slow' because she couldn't figure out things and kept on bringing to my attention every little complaint she had.

Intervention Week: Negative about Others: Feeling: Angry, Upset Thinking: Annoyed. Why can't people leave me alone?

\section{Summary}

People were asking me for (what I thought) "unnecessary" help. One person asked for too many items to carry. Another person seemed rude and "pushy". Applying the Bridge Technique began with me thinking of alternate explanations for my thinking. My attitude changed and I felt less stress and anger toward the patrons. Finding my job a little more enjoyable and I show less "attitude" toward the patrons. It took me a while to change my thinking (+/-20min) but eventually it worked. I experienced less anger and annoyance, and I helped more patrons out after applying the Bridge Technique.

The following student used a 10-point rating scale to monitor the intensity of the negative feelings:

First day of baseline: Child I was supervising in class

Feeling: After three times asking him to be quiet I was really angry. I knew other kids needed to finish their work or their parents would be angry with me.

Thinking: I thought I should yell at him or smack his hand with my stick acting out: I told him to "shut up". This made me feel terrible.

First day of intervention trials.

Feeling: Stress and anger

Thinking: I remembered that I must try to think logically so my illogical turned to logical and I crossed the red and blue bridges. I thought he was just a child who hasn't learned enough yet to be good and I shouldn't be affected by his misbehaving (Table 2).

The present comparative study on the cognitive profile of the elderly from rural and urban West Bengal demonstrates that rural elderly of both sexes experienced greater cognitive adversities measured in terms of cognitive impairment, compared to their urban counterparts. Intuitively, among the rural elderly poor socioeconomic status leading to economic dependence coupled with low educational status could perpetuate mental health adversities in the form of problems pertaining to cognitive impairment. A well-designed epidemiological study on this aspect investigating cognitive adversities of the rural elderly of West Bengal and identification intervention points to mitigate this problem is of urgent necessity.

\section{Further research}

The current results indicate that the conceptual level of the theory is appropriate for psychology majors and those they are able to relate favorably to the idea of a mental "bridge" that can be crossed to transform their negative mental state into positive. In this case all students chose to do the project even though there were alternatives provided. Further research could establish whether non-majors in psychology can relate to the language of the threefold-self. In addition, the parameters need to be investigated, especially whether individuals are able to persist in the bridge technique over time, or whether additional elaboration of the theory is needed for that purpose. Gender differences also need to be explored since social norms for expressing anger differ for men and women.

In a current project on daily emotional spin cycle patterns conducted by this author, 1200 people chose to answer a survey posted on a Web site. Several of the survey questions are closely related to the way the students in the current article reported their emotional spin cycle (see samples above). The data included a check response on gender of the respondent ("Male" or "Female"). Table 1 is based on the data of the Web survey. Participation was voluntary (no compensation) and anonymous. The sample was composed of 1164 respondents. Their age ranged from 19 to 70 , with the majority aged 20 to 55 . There were 586 men and 578 women in the sample. An example of the statistical analyses performed on one item is presented in the Appendix (Table $3)$. 
In general, gender differences in self-reported emotions interact with the characteristics of particular emotions, possibly related to cultural norms of emotional expression ${ }^{22}$. For instance significantly more men report feeling rage (40 percent) and enjoying fantasies of violence ( 15 percent) than women, though the absolute differences are not large (about 10 percent). On the other hand, significantly more women report "feeling angry because someone hurts your feelings" (14 percent) than men (11 percent). The reverse is the case for "feeling angry because someone tries to stop you from doing what you want" (18 vs. 12 percent). Again the difference is small though highly reliable statistically.

Further investigation can reveal the effectiveness of the bridge technique with negative habits of different strength. It is to be expected that long-term habits of verbalization that have become habituated and sub-conscious or unattended to, would be more resistant to the bridge technique. Appropriate priming may be effective in bringing awareness of such well-established habits, thereby making the bridge technique more effective. Several self-reports mentioned a generalization effect when they used the bridge technique successfully, resulting in good feelings about self (e.g. During times like this I can look back and feel proud as I was resisting the negative for a positive outcome"). Tracking such changes over time may indicate whether the bridge technique is specific to the situation where it is used, or whether it also transfers to similar situations, as indicated by one individual as follows:

"I have discovered a lot about myself. In fact I feel I have gained more self-control as I now have the knowledge to stay on the positive side of the emotional spin cycle. My friends and family have also seen a drastic improvement in my ability to cope with my problem situations. In the past I was easily aggravated and I would say and do destructive things. I now produce positive feelings, thoughts and actions."

\section{Acknowledgments}

None.

\section{Conflicts of interest}

Author declares there are no conflicts of interest.

\section{Funding}

None.

\section{References}

1. Skinner BF. Verbal Behavior. Appleton-century-Crofts, New York, USA. 1957

2. Mahl GF. Measuring the patient's anxiety during interviews from "Expressive" aspects of his speech. Transactions of the New York Academy of Sciences. 1959;21(3):249-257.

3. Gottschalk LA. Content Analysis of Verbal Behavior: New Findings and Clinical Applications. Lawrence Earlbaum Associates, New Jersey, USA. 1995. p. 240 .

4. Beck AT. Cognitive Therapy and the Emotional Disorders. (1st edn) International Universities Press, USA. 1976. p.368.
5. Ericsson KA, Simon HA. Protocol Analysis: Verbal reports as data. (Rev edn), The MIT Press, Cambridge, Massachusetts, London, England. 1984.

6. Vygotsky LS. Thought and Language. In. Hanfmann E, Vakar G \& Kozulin A (Eds.). (Rev \& Expanded edn) MIT Press, Cambridge. 1962.

7. Meichenbaum D. Cognitive-Behavior Modification: An Integrative Approach. Springer, New York, USA. 1977. p.305.

8. Ellis A. Feeling Better, Getting Better, Staying Better: Profound Selfhelp Therapy for your Emotions. Impact Publishers, California. 2001. p. 272 .

9. Watson D, Tharp R. Self-Directed Behavior: Self-Modification for Personal Adjustment. (10th edn), Cengage Learning, USA. 2014. p.432.

10. James L, Nahl D. Dealing with Stress and Pressure in the Vehicle: Taxonomy of Driving Behavior: Affective, Cognitive, Sensorimotor. In Rothe JP (Ed.), Driving Lessons: Exploring Systems that Make Traffic Safer. University of Alberta Press, Edmonton, Canada. 2002. p.21-50.

11. James L, Nahl D. A New Paradigm for a Global Lifelong Driver Education Curriculum International Association for Driver Education IVV, Road Safety Conference SAFEX, Driving Magazine Croatia, UK. 2004.

12. Jakobovits LA, Nahl-Jakobovits D. Learning the Library: Taxonomy of Skills and Errors. IN College and Research Libraries. 1987;48(3):203-214.

13. Nahl D. Affective and Cognitive Information Behavior: Interaction Effects in Internet Use. In 68th Annual Meeting of the American Society for Information Science and Technology (ASIST). 2005;42(1).

14. Labov W, Fanshel D. Therapeutic Discourse: Psychotherapy as Conversation. Academic Press, New York, USA. 1977. p.373-377.

15. Searle JR. Speech Acts: An Essay in the Philosophy of Language. Cambridge University Press, Cambridge, UK. 1969. p.203.

16. Austin J L. The william james lectures delivered at harvard university, in 1955 (linguistics) In: Urmson JO (Ed.), How to Do Things with Words. (1st edn), Oxford University Press, New York. 1965. p.166.

17. James L, Nahl D. Road Rage and Aggressive Driving: Steering Clear of Highway Warfare. (1st edn) Prometheus Books, New York, USA. 2000. p. 275 .

18. Leon J. Affective and cognitive resistance to health behaviors. Department of Psychology, University of Hawaii, USA. 1985.

19. Krathwohl DR, Bloom BS, Masia BB. Taxonomy of Educational Objectives. Handbook II: Affective Domain. David McKay, New York, USA. 1964. p.196.

20. Bloom BS. Taxonomy of Educational Objectives: The Classification of Educational Goals. Handbook I: Cognitive David McKay, Domain. New York. 1956.

21. Merrill MD. Psycho motor Taxonomies, Classifications, and Instructional Theory. In Singer RN, (Ed.) The Psychomotor Domain: Movement Behavior. Lea \& Febiger, Philadelphia, USA. 1972.

22. Markus HR, Kitayama S. The Cultural Shaping of Emotion: A Conceptual Framework. American Psychological Association, Washington DC, USA. 1994. p.339-351. 